\title{
Using Reflectance Spectroscopy and Artificial Neural Network to Assess Water Infiltration Rate into the Soil Profile
}

\author{
Naftali Goldshleger, ${ }^{1,2}$ Alexandra Chudnovsky, ${ }^{3}$ and Eyal Ben-Dor ${ }^{4}$ \\ ${ }^{1}$ Soil Erosion Research Station, Soil Conservation and Drainage Division, Ministry of Agriculture, c/o Rupin Institute, \\ Emek-Hefer 40250, Israel \\ ${ }^{2}$ Ariel University Center of Samaria, Israel \\ ${ }^{3}$ Department of Environmental Sciences, Weizmann Institute of Science, Rehovot 76100, Israel \\ ${ }^{4}$ Department of Geography and the Human Environment, Tel-Aviv University, Remote Sensing and GIS Laboratory, \\ P.O. Box 39040, Ramat Aviv, Tel Aviv 69978, Israel \\ Correspondence should be addressed to Naftali Goldshleger, goldshleger@gmail.com
}

Received 8 November 2011; Revised 6 April 2012; Accepted 18 June 2012

Academic Editor: Raphael Viscarra Rossel

Copyright () 2012 Naftali Goldshleger et al. This is an open access article distributed under the Creative Commons Attribution License, which permits unrestricted use, distribution, and reproduction in any medium, provided the original work is properly cited.

\begin{abstract}
We explored the effect of raindrop energy on both water infiltration into soil and the soil's NIR-SWIR spectral reflectance (1200$2400 \mathrm{~nm}$ ). Seven soils with different physical and morphological properties from Israel and the US were subjected to an artificial rainstorm. The spectral properties of the crust formed on the soil surface were analyzed using an artificial neural network (ANN). Results were compared to a study with the same population in which partial least-squares (PLS) regression was applied. It was concluded that both models (PLS regression and ANN) are generic as they are based on properties that correlate with the physical crust, such as clay content, water content and organic matter. Nonetheless, better results for the connection between infiltration rate and spectral properties were achieved with the non-linear ANN technique in terms of statistical values (RMSE of $17.3 \%$ for PLS regression and $10 \%$ for ANN). Furthermore, although both models were run at the selected wavelengths and their accuracy was assessed with an independent external group of samples, no pre-processing procedure was applied to the reflectance data when using ANN. As the relationship between infiltration rate and soil reflectance is not linear, ANN methods have the advantage for examining this relationship when many soils are being analyzed.
\end{abstract}

\section{Introduction}

1.1. Physical Crust and Infiltration Rate. The main cause of runoff from rain and overhead irrigation is the generation of a structural soil crust $[1,2]$. Crust formation results from a combination of the kinetic energy impact of raindrops and the level of stability of the soil aggregates $[1,2]$. The structural crust is generated within minutes and significantly reduces soil infiltration rate (IR). Assessment of this IR is vital for sustainable land management, especially in semiarid and arid regions where harsh climatic conditions cause soil degradation and damage to agricultural areas. Thus, monitoring of soil crust conditions is essential for the proper management of soils, from both an agricultural and landdegradation perspective.
1.2. Reflectance Spectroscopy. Previous research has shown that reflectance spectroscopy can provide a valuable means of assessing the condition of the soil crust and estimating related problems. The spectral reflectance provides information about the chemical and physical conditions of bulk matter (in the laboratory) and of the surface (in the field), which can then be used to assess the condition of the soil crust and estimate the related problem (e.g., infiltration rate, runoff potential) $[3,4]$. Two important mechanisms which usually occur during crust formation can be independently tracked by spectroscopy: changes in particle size and changes in mineral distribution on the crust surface, both of which are associated with albedo $[5,6]$.

Recent studies conducted by Goldshleger et al. [5, 7-9] and Ben-Dor et al. [10] have shown that choosing specific 
wavelengths is essential for IR assessment. The authors generated a spectral library for each soil type that was subjected to various rain energies. They showed that different regression correlations exist between the spectral reading and crust status for each studied soil. Moreover, the reflectance properties of soils could be used as indicators of the crusting process generated by raindrop impact $[5,8,10,11$.

\subsection{Calibration Development: Linear and NonLinear Model-} ing Techniques. Most of the aforecited studies were used near infrared spectroscopy (NIRS) to develop a spectral-based model for the assessment of soil crust status. NIRS is known as an analytical technology that enables many disciplines to conduct real-time monitoring procedures [12]. There has been a rise in recent years in the use of qualitative and quantitative applications of NIRS to determine quality indicators for soils [13] and sediments [14]. In most cases, NIRS requires a reference technique to build up calibration routines and to guarantee the proper maintenance of an established calibration with reference to outlier detection and troubleshooting. The main issues, therefore, include spectral measurements in the VIS-NIR-SWIR regions (400$2400 \mathrm{~nm}$ ), spectroscopic calibration, spectral preprocessing, and validation of the calibration models. Finally, it should be emphasized that NIRS is not a routine tool but at the same time has tremendous potential, because it can provide unique information that is not accessible with any other technique [15].

Constituents and properties of soils and/or sediments analyzed by reflectance spectroscopy combined with reference calibration modeling have included moisture, iron oxides, organic and clay matter contents, organic C, N, P, S, $\mathrm{K}$ and $\mathrm{Ca}$, and aggregate size [6, 18-23]. Furthermore, NIRS strategy has been used to determine the relationship between spectral response and crust status [24, 25]. Quantitative modeling of VIS-NIR-SWIR spectra is frequently performed using a variety of multivariate techniques, including stepwise regression, partial least-squares (PLS) regression, modified PLS, classification and regression trees, and principal component regression. All of these techniques have been applied to model the relationship between reference chemical and physical soil properties and spectral data $[26,27]$. The linear PLS regression approach has been used to model several response variables simultaneously while effectively dealing with strongly collinear and noisy independent variables [28]. Recently, Viscarra Rossel et al. [22, 23] showed that PLS regression techniques can be used successfully for the prediction of soil properties from reflectance, even if the soils are of different types and nature. They collected spectra and chemical properties of more than 2,000 soils worldwide and demonstrated the generation of a generic model for all of the selected soils, regardless of type. Brown et al. [29] and Brown [30] built a global soil-spectral library to estimate the amount of clay-fraction material.

A neural network is a "machine" that is designed to model the way in which the brain performs a particular task or function [31]. Artificial neural networks (ANNs) have the ability to model linear or non-linear relationships between a set of input and output variables [32]. Viscarra Rossel and Behrens [23] compared several data-mining techniques with PLS, and Brown et al. [29] often use data mining as a standard method in their studies. Although these applications are in the soil sciences, we thought it would be of interest to examine their performance on soil material and especially on a property that exhibits high variation-the spectral signature of the soil's physical crust. Farifteh et al. [33] showed that both ANN and PLS regression methods have great potential for estimating IR. Moreover, both methods showed similar accuracy in predicting soil salinity.

Objective. In this study, the spectral reflectance of crusting soils (characterized by large variation) was analyzed in order to assess applicable models for the prediction of IR values via non-linear ANN and linear PLS regression. Four soils from Israel and three soils from the US were selected as the test population for examination. ANN and PLS regression results for the selected soil populations were also compared to evaluate the performance of the different procedures.

\section{Materials and Methods}

2.1. Soil Samples. Four soils from Israel and three from the US, ranging from sandy to clayey, were used for this study. Table 1 provides their physical and chemical compositions.

\subsection{Experimental Rainstorm Simulations (IR Measurements).} The soil samples were sieved through $2 \mathrm{~mm}$ mesh and identically packed into $30 \times 50 \times 4 \mathrm{~cm}$ perforated soil boxes over a layer of coarse sand. The boxes were placed on a carousel on a $5 \%$ slope, five boxes containing the same soil per run and were subjected to simulated rainstorm [34] using distilled water. The water that percolated through the soil and sand layers out of the perforated soil box during a continuous simulated rainstorm approximately represented instantaneous IR. The IR of the soil was continuously measured during the rainstorm. At first, the simulated rainstorm provided a fogtype rain (no energy), with intensity similar to the initial IR of each soil as measured previously. This storm lasted until the measured rate of percolation reached that of the previously measured IR for the simulated rainstorm intensity. Then the rainfall was stopped and the soil boxes were left until drainage from all boxes ceased. One soil box was randomly selected. The remaining soil boxes were subjected to a continuous rainstorm at an intensity approximately similar to the initial IR of the soil, with an energy of $\sim 22.3 \mathrm{~J}$. The instantaneous simulated rainstorm was calculated by Morin et al. [34] and the accumulated (immediate) energy of each rainstorm depended on the depth intensity $(\mathrm{mm})$ of the designed storm. For each of the remaining soil boxes, increasing levels of cumulative rainstorm energies (achieved by increasing time of exposure to the rainstorm) were applied (Tables 2(a) and 2(b)). Two consecutive runs were conducted for each soil, resulting in 10 soil boxes with increasing levels of crusting (due to increasing levels of cumulative rainstorm energies). After each rainstorm for a given soil, the boxes were oven dried for $48 \mathrm{~h}$ at $105^{\circ} \mathrm{C}$ (simulating dry field 
TABLE 1: Selected characteristics of the soil samples.

\begin{tabular}{|c|c|c|c|c|c|c|c|c|}
\hline \multirow[b]{2}{*}{ Soil symbols } & \multirow{2}{*}{$\begin{array}{l}\text { Soil series Israel* } \\
\text { USA }^{* *}\end{array}$} & \multirow{2}{*}{$\begin{array}{l}\text { Soil classification } \\
\text { USDA** }\end{array}$} & \multicolumn{3}{|c|}{ Mechanical composition (\%) } & \multicolumn{3}{|c|}{ Chemical properties } \\
\hline & & & Sand & Silt & Clay & $\begin{array}{c}\mathrm{OM} \\
\mathrm{g} \mathrm{kg}^{-1}\end{array}$ & $\begin{array}{l}\mathrm{CaCO}_{3} \\
\mathrm{~g} \mathrm{~kg}^{-1}\end{array}$ & $\begin{array}{c}\text { ESP } \\
\%\end{array}$ \\
\hline Is $1(G)$ & Grumosol & Typic chromoxerets & 21.7 & 25.4 & 52.9 & 12.4 & 114.4 & 1.0 \\
\hline Is $2(\mathrm{~S})$ & Loamy loess & Calcic haploxeralf & 37.7 & 40.6 & 21.7 & 9.1 & 108.2 & 2.2 \\
\hline Is $3(\mathrm{~A})$ & Terra rossa & Lithie ruptie xerochrept & 2.6 & 32.7 & 64.7 & 22.6 & 146 & 0.5 \\
\hline Is4(E) & Hamra & Typic Rhodoexeralf & 79 & 10 & 11 & 8.2 & 22.2 & 0.8 \\
\hline Am1 & Reiff $\mathrm{cm}^{* * *}$ & Mollic xerofluevents & 29 & 54 & 17 & 19.4 & 66.4 & 0.72 \\
\hline Am2 & Reiff om**** & Mollic xerofluevents & 27 & 55 & 18 & 23 & 64.2 & 1.17 \\
\hline Am3 & Capay & Typic xerofluevents & 7 & 62 & 31 & 14.4 & 77.1 & 0.73 \\
\hline
\end{tabular}

TAвLE 2: Cumulative rainfall energies $\left(\mathrm{J} \mathrm{mm}^{-1} \mathrm{~m}^{-2}\right)$ and subsequent infiltration rates (IR) for each soil: (a) Israeli soils. (b) US soils.

(a) Cumulative rainfall energies $\left(\mathrm{J} \mathrm{mm}^{-1} \mathrm{~m}^{-2}\right)$ and the subsequent IR for Israeli soils

\begin{tabular}{|c|c|c|c|c|c|c|c|}
\hline \multicolumn{2}{|c|}{ Is1-Grumosol } & \multicolumn{2}{|c|}{ Is2-loess } & \multicolumn{2}{|c|}{ Is3-Terra Rossa } & \multicolumn{2}{|c|}{ Is4-Hamra } \\
\hline IR $\mathrm{mm} \mathrm{h}^{-1}$ & $\mathrm{~J} \mathrm{~mm}^{-1} \mathrm{~m}^{-2}$ & IR $\mathrm{mm} \mathrm{h}^{-1}$ & $\mathrm{~J} \mathrm{~mm}^{-1} \mathrm{~m}^{-2}$ & IR $\mathrm{mm} \mathrm{h}^{-1}$ & $\mathrm{~J} \mathrm{~mm}^{-1} \mathrm{~m}^{-2}$ & $\mathrm{IR} \mathrm{mm} \mathrm{h}^{-1}$ & $\mathrm{~J} \mathrm{~mm}^{-1} \mathrm{~m}^{-2}$ \\
\hline 205 & 0 & 207 & 0 & 145 & 0 & 46 & 0 \\
\hline 173 & 134 & 159 & 70 & 69 & 252 & 32 & 280 \\
\hline 154 & 200 & 94.3 & 109 & 70 & 380 & 28.5 & 420 \\
\hline 69 & 265 & 36.8 & 145 & 49,5 & 506 & 24 & 850 \\
\hline 41 & 400 & 32.2 & 216 & 39 & 1012 & 21 & 1120 \\
\hline 30 & 530 & 22 & 290 & 30 & 1460 & 17 & 1550 \\
\hline 17 & 665 & 10.6 & 506 & 19.6 & 2016 & 11.5 & 1700 \\
\hline 15 & 800 & 8.3 & 613 & 13.8 & 2832 & 11.5 & 2300 \\
\hline 10 & 1590 & 7.4 & 1012 & 9.4 & 4060 & 7 & 3200 \\
\hline & 2522 & & 1842 & 5.8 & & 3.5 & \\
\hline
\end{tabular}

(b) Cumulative rainfall energies $\left(\mathrm{J} \mathrm{mm}^{-1} \mathrm{~m}^{-2}\right.$ ) and the following (IR) for American soils

\begin{tabular}{|c|c|c|c|c|c|}
\hline \multicolumn{2}{|c|}{ Am1-Reiff ${ }_{\mathrm{cm}}$} & \multicolumn{2}{|c|}{ Am2-Reiff ${ }_{\text {om }}$} & \multicolumn{2}{|c|}{ Am3-Capay } \\
\hline $\mathrm{IR} \mathrm{mm} \mathrm{h}^{-1}$ & $\mathrm{~J} \mathrm{~mm}^{-1} \mathrm{~m}^{-2}$ & IR $\mathrm{mm} \mathrm{h}^{-1}$ & $\mathrm{~J} \mathrm{~mm}^{-1} \mathrm{~m}^{-2}$ & IR $\mathrm{mm} \mathrm{h}^{-1}$ & $\mathrm{~J} \mathrm{~mm}^{-1} \mathrm{~m}^{-2}$ \\
\hline 84 & 0 & 207 & 0 & 120 & 0 \\
\hline 53 & 70 & 92 & 145 & 78 & 141 \\
\hline 44 & 136 & 62 & 216 & 32 & 210 \\
\hline 30 & 200 & 35 & 290 & $15 / 6$ & 280 \\
\hline 26 & 240 & $28 \mathrm{~s}$ & 335 & 11.5 & 350 \\
\hline 17 & 270 & 23 & 357 & 7.8 & 420 \\
\hline 11 & 340 & 18 & 435 & 4.1 & 560 \\
\hline \multirow[t]{3}{*}{5.5} & 540 & & 470 & & \\
\hline & 1560 & & 723 & & \\
\hline & & & 1810 & & \\
\hline
\end{tabular}

conditions) and subjected to spectral reading of the dry surface reflectance.

2.3. Spectral Measurements. The spectral reflectance measurements were carried out with a Quantum 1200+ laboratory spectrometer. The instrument was optimized to the
NIR-SWIR region (1200-2400 nm) with a bandwidth of $10 \mathrm{~nm}$ (1,200 spectral bands in total). $\mathrm{BaSO}_{4}$ powder was used as a white reference to enable conversion of the measured data into reflectance values. An average spectrum for every cumulative level of rain energy was calculated, using five replicates. 
2.4. Data Analyses. The IR and reflectance data were analyzed to generate a spectral-based model for the prediction of IR solely from spectral measurements. Importantly, for the ANN analysis, it is impossible to include the array of all measured wavelengths and it must be reduced based on number of observations (e.g., degrees of freedom). Therefore, first, the most significant wavelengths were identified (as described in the section below) and modeling was run based on this selection. For comparison, we also apply linear PLS regression analyses to assess IR values of soils.

Reflectance spectra of seven soils (64 samples) and their corresponding IR were carefully checked for errors in the measured IR values (e.g., suspiciously large or small measured values of IR for the specific sample, $Y$-variable) and soil reflectance spectra (NIR-SWIR range, $X$-variables). For both variables, no outliers were detected.

It is important to mention that for ANN modeling, raw IR was used whereas for PLS was based on log IR value were used. In addition raw spectra were used, for ANN modeling, whereas for PLS spectra were considered using the second derivative on absorbance. Both, PLS and ANN were run on the same reduced spectral range (48 wavelengths).

2.5. Wavelength Selection for a Model. We investigated the influence of selecting individual wavelengths to generate an optimal calibration model to assess IR in soils. To that end, we ran PLS models on the entire wavelength region with the aim of identifying the significant wavelengths. Significant variables were estimated using Martens' uncertainty test [35], which assesses the stability of the PLS regression. Many plots and results are associated with the test, which allows estimating the model's stability, identifying perturbing samples or variables, and selecting significant $X$ variables. The test is performed with cross-validation and performed first on the whole spectral range. Therefore, each PLS model (raw and preprocessed) was first run on the whole range of spectra, and, then, restricted to significant wavelengths which were identified based on Martens' test. We also include additional wavelengths (e.g., supervised/manual selection) based on knowledge of soil absorbencies (e.g., absorbance of clay at $2200 \mathrm{~nm}$ was included). Then the model was run solely on the selected wavelengths and reassessed until acceptable results (in terms of model stability and prediction accu-racy) were achieved. All data management, calculations, PLS analyses, and different spectral pretreatments were performed using version 9.2 of the chemometric software Unscrambler (Camo Software, Oslo, Norway).

2.6. Modeling Approach: PLS. PLS were used to model correlation between soil reflectance spectra and IR. The PLS regression is based on latent variable decomposition of two blocks of variables, the $X$ and $Y$ matrices, which contain spectral data and any reference chemical variable, respectively. The objective of the regression is to locate small numbers of PLS components that efficiently predict $Y$ when $X$ is used [35]. PLS analysis establishes a relationship between the predictor block, $X$-matrix, and the response, $Y$, via an innerrelation of their scores. The $X$-scores, describe the object variation in the predictor block (the spectral matrix in this case) and the corresponding variation in the response block by the $Y$-scores. What PLS does is to maximize the covariance between these inner variables (also called latent structures). A weight vector is calculated for each PLS component that assess the contribution of each $X$-variable to the explanation of $Y$ in that particular component.

The PLS regression model was constructed by crossvalidation. Due to the limited number of samples, statistical parameters for the calibration model (49 samples) were calculated by leave-one-out-cross-validation (only one sample at a time is kept out of the calibration and used for prediction). The model was subjected to external validation, performed on a set of 11 samples, selected from the calibration matrix, and isolated as a test set. The test set was the same for both PLS and ANN models. Furthermore, reflectance spectra were considered using the second derivative on absorbance as a preprocessing technique based on Goldshleger et al. [9].

2.7. Modeling Approach: ANN. The ANN has three layers of neurons: input, hidden, and output [31]. All of the neurons in each layer are connected to neurons in the adjacent layer. Neurons in the hidden layer perform two tasks: they sum the weighted inputs and, then, pass the resulting summation to neurons in the adjacent layer through a sigmoidal processing function known as the activation function. This function determines the neuron's output and generally maps the interval $(-\infty, \infty)$ onto $(0,1)$. The weighted inputs to the hidden and output neurons can be adjusted to shift the whole summation in a direction that will aid in minimizing errors. The activation function essentially forces each neuron's summation between set limits, 0 and 1, before it is passed to the neurons in the next layer. The most common learning algorithm is based on supervised error backpropagation, in which a data set of system inputs and outputs (the training set) is presented to a neural network having initial assumed connection weights. An error is calculated by comparing the actual outputs to those calculated, and, accordingly, the connection weights are modified to decrease the sum of squared errors. This training procedure is carried out repeatedly until the error converges to a small appreciable value. The network is tested by processing another set of inputs (the test set) and comparing the network output with the test set. If the resulting error is sufficiently small, the network is considered trained and it may be used for predicting outputs. The numbers of neurons used for training the networks were varied systematically between four and 12 to allow subsequent selection of the most appropriate network size based on the performance on the test data set [36]. For ANN modeling, the computer software MatLab, in-house programs and the Neural Network Toolbox were used (The Mathworks Inc., Natick, MA, USA).

For each scale of the study, each data set was divided into three subsets, one for training (half of input data), one for validation (a quarter of the input data), and one for testing (a quarter of the input data). The Levenberg-Marquardt algorithm [37], which provides a fast optimization, was 
used for network training. The performance of a trained network was assessed by comparing the mean squared error (MSE) and root mean squared error (RMSE) calculated from training, validation, and testing data subsets. Only a training data subset is used for updating the network weights and biases. During training, error with respect to validation data subset is monitored. When the validation error increases for a specified number of iterations, the training is stopped. Error with respect to testing data subset is not monitored during training but is quantified to assess the final performance of a trained ANN model.

For the ANN analysis, the data of all spectral measurements were manually divided into three subsets: a calibration set (training set) containing 37 samples (to establish the model), a validation set, comprised of 12 samples (to validate the training set), and an external test set comprised of 11 samples (to examine the predictive ability of the entire model). Note that the same test set was used for PLS analyses. In our selection of calibration/validation and test sets, soil samples were comparably presented in terms of means of soil type and of their measured IR.

The predictive capability of all models was compared in terms of the relative standard error for both the calibration and validation sets (denoted as RMSECV (\%) and RMSEP $(\%)$ :

$$
\% \text { RMSE }=\left[\frac{\Sigma\left(X_{m}-X_{P}\right)^{2}}{\Sigma X_{m}^{2}}\right]^{1 / 2} \times 100 .
$$

In addition we used the ratio of prediction to deviation (RPD), which is defined as the ratio of the standard deviation of the reference values (e.g., IR) to the root mean square error of cross-validation (RMSECV) or prediction (RMSEP) [38]. An RPD value below 1.5 was taken to indicate that the model is unusable, whereas above 3.0 was considered to be excellent.

\section{Results and Discussion}

3.1. Spectral Changes. Soil reflectance is a product of particle size distribution (expressed as baseline height or physical albedo effect) and chemical composition (expressed as absorption peaks). In all soils tested to date, the soil crust chroma (expressed by albedo changes) becomes brighter as the cumulative rain energy increases. Moreover, a noticeable sequence of albedos is observed in all soils [9]. For example, in Israeli soils, the cumulative energy level ranges from lowest (baseline around $0.25,0.15,0.4$, and 0.55 ) to highest (baseline around $0.4,0.3,0.5$, and 0.7 ) for Grumusol, Terra Rossa, Loess, and Hamra soils, respectively, [8].

Figure 1 provides the reflectance spectra in the NIR range (1200-2400 nm) of each energy treatment used on all four soils: Hamra, Terra Rossa, Loess, and Grumosol. Hamra is a sandy soil with a relatively high quartz content (90\%) and a small percentage of clay (5\%); Terra Rossa is a type of red clay soil produced by the weathering of limestone. Loess is an aeolian sediment formed by the accumulation of wind-blown silt, typically in the $20-50 \mu \mathrm{m}$ size range, $20 \%$ or less clay, and the remainder equal parts sand and silt.
Grumosol has a high content of expansive clay over 50\% It can be concluded that one major crust-formation pattern is exhibited in soils whereas an exceptional pattern can be obtained in nonclayey soils. The increasing accumulated rain energy applied to these soils caused an increase in albedo patterns related to increasing clay content. This is a result of fine particle size segregation in the crusting process where clay minerals usually occupy the fine particle fraction. Furthermore, there is evidence of changes in the crust with a rise in rain energy (Figure 1), including demolition of the clay layer or washing away of the sand particles. The above results demonstrate the usefulness of reflectance as a tool to monitor the crust formation process in a particular soil.

3.2. Calibration Modeling Using PLS Analyses. A much clearer picture of spectroscopic-IR changes is obtained from the plot of factor loadings ( $\mathrm{LV}$, or regression coefficients) versus wavelengths of the best pre-processing technique (second derivative of absorbance run on selected wavelengths) and shown in Figure 2. The wavelengths selected for the IR prediction were based on Marten's test selection and were centered at 1230,1385, 1390-1407, 1436, 1447, 1850, $1866,1912,1940,2016,2180,2200,2250,2292,2315$, and $2351 \mathrm{~nm}$. These wavelengths can be spectrally assigned to $\mathrm{OH}$ in water (1400 and $1900 \mathrm{~nm}$ ) [39], organic matter (2016 and $2290 \mathrm{~nm}$ ) [6], and $\mathrm{Al}-\mathrm{OH}$ in clay minerals (2200 and $2250 \mathrm{~nm})[39,40]$. These are general features for all soil types and therefore, can be identified as a generic spectral footprint for the prediction of IR.

Using PLS analyses, the best model was generated when the first derivative was applied to the reflectance values but run only using significant wavelengths (Marten's test). Figure 3 upper panel shows the relationship between measured and predicted values for cross-validation. The statistics obtained were RMSECV of $10.2 \%$ and $13.6 \%$ for all soils, a slightly larger $R^{2}$ of 0.70 and RPD values between 2.0 and 2.1. Slightly but not significantly better models could be achieved for the data set without IS4 in the cross-validation data set (54 samples in the cross-validation set), with $R^{2}$ increasing to 0.73 . The lower panel of Figure 3 shows a plot of this best fit model when applied on an external mixed data set measured by LT spectrometer (11 samples). The linear plot exhibits a slope of $0.75, r^{2}=0.46$ and with a relatively high RMSEP (\%) of $15 \%$.

3.3. Calibration Modeling Using the ANN Approach. Figures 4 and 5 present the measured versus predicted values for each soil type for the calibration and test sets, respectively, using the ANN approach. The test set was representative of the constructed calibration model and included different soil types covering various IR values (i.e., wide dynamic range). Figure 5 shows the $R^{2}$ and RMSE values for the test set $\left(R^{2}=\right.$ 0.91$, RMSE $=10.6 \%)$, whereas for the calibration set, $R^{2}=$ $0.96($ RMSE $=6.5 \%)$. These results indicate that the ANN model learned the system well and had good generalization and assessment abilities. In contrast, when PLS model was run on the same test set (see Figure 3 lower panel for comparison), lower values of $R^{2}(0.46)$ and RMSEP (15\%) were 

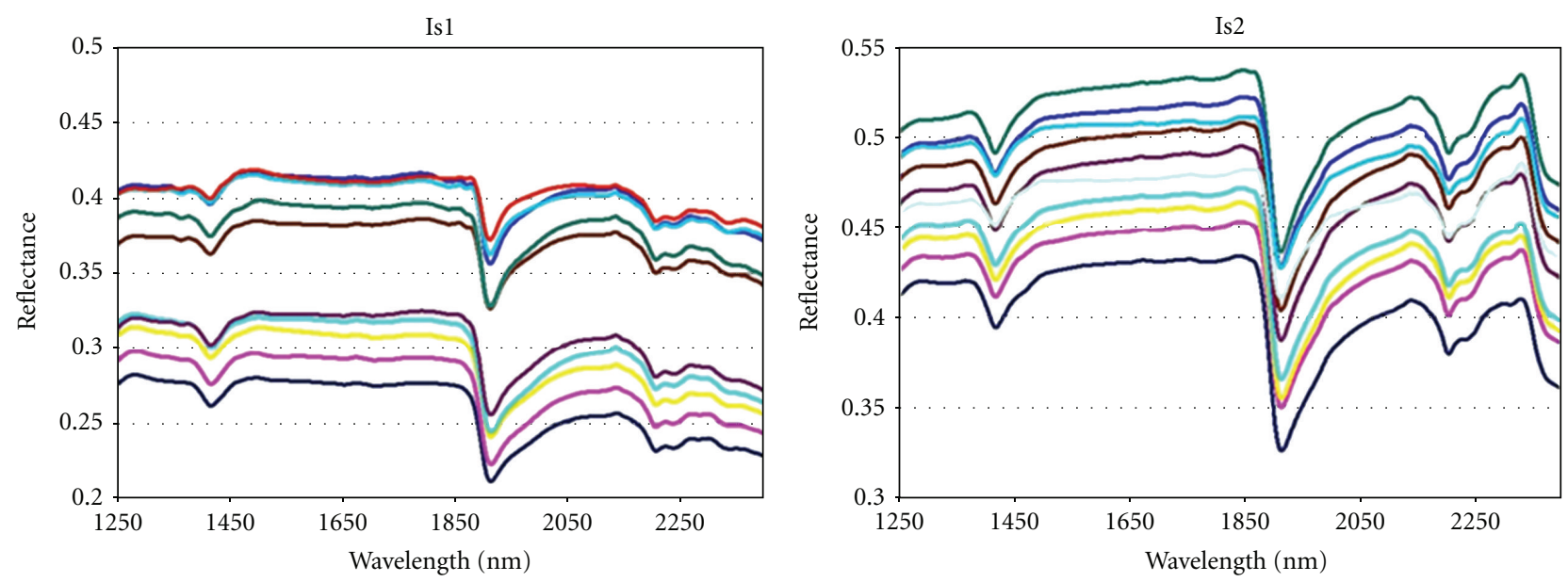

Rain energy $\left(\mathrm{Jmm}^{-1} \mathrm{~m}^{-2}\right)$

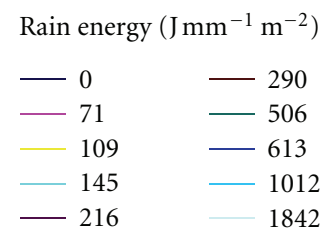

$\begin{array}{ll}-0 & -530 \\ -134 & -665 \\ 200 & -800 \\ 265 & -1590 \\ -400 & -2522\end{array}$

(a)

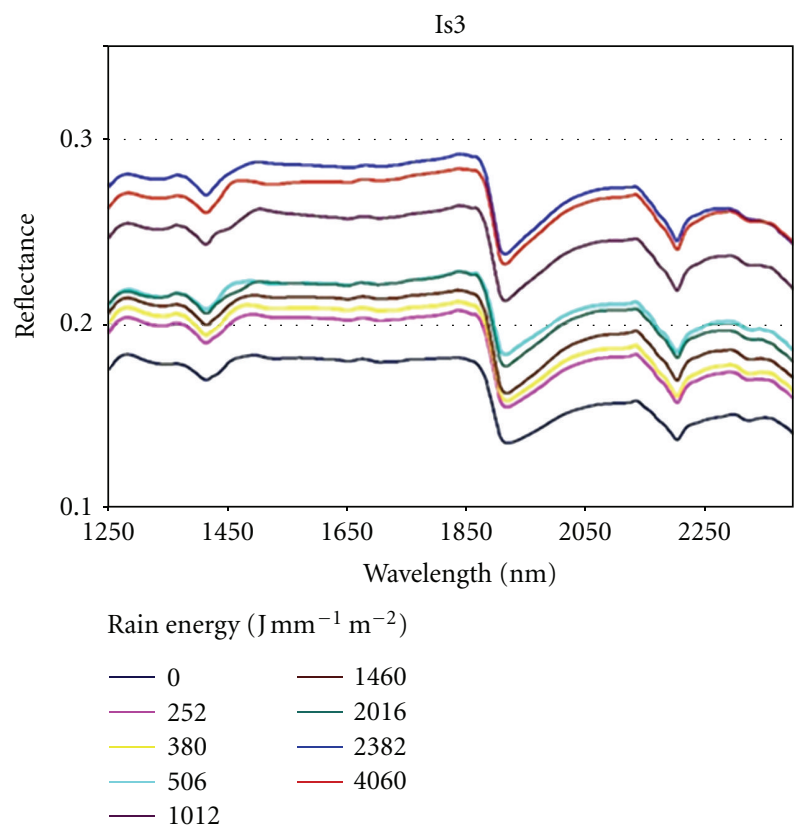

(c)

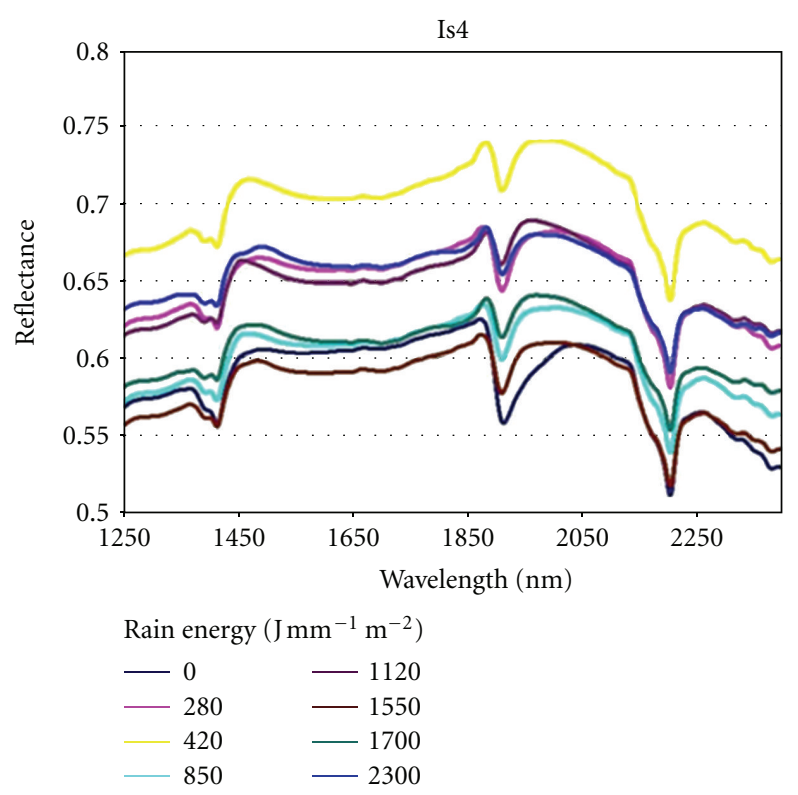

(d)

FIGURE 1: Spectral reflectance of each cumulative (rain) energy level for Israeli soil types.

accepted. In this regard, the ANN approach gives better results for the assessment of IR than the PLS regression analysis. Nevertheless, both methods indicate the possibility of generating a generic model designed to assess IR, even if an outlier group (in terms of crust formation) is involved (in our case, Is4) in the cross-validation or calibration/validation test set. Interestingly, when the same soil samples were combined in the calibration, validation, and test sets to assess IR using both PLS regression and ANN analyses, the latter provided significantly better accuracy.

In our analysis, the major advantage of ANN is the utilization of an independent test set with raw IR values, eliminating the need to apply any data pre-processing to the reflectance spectra. As the relationship between IR and soil 


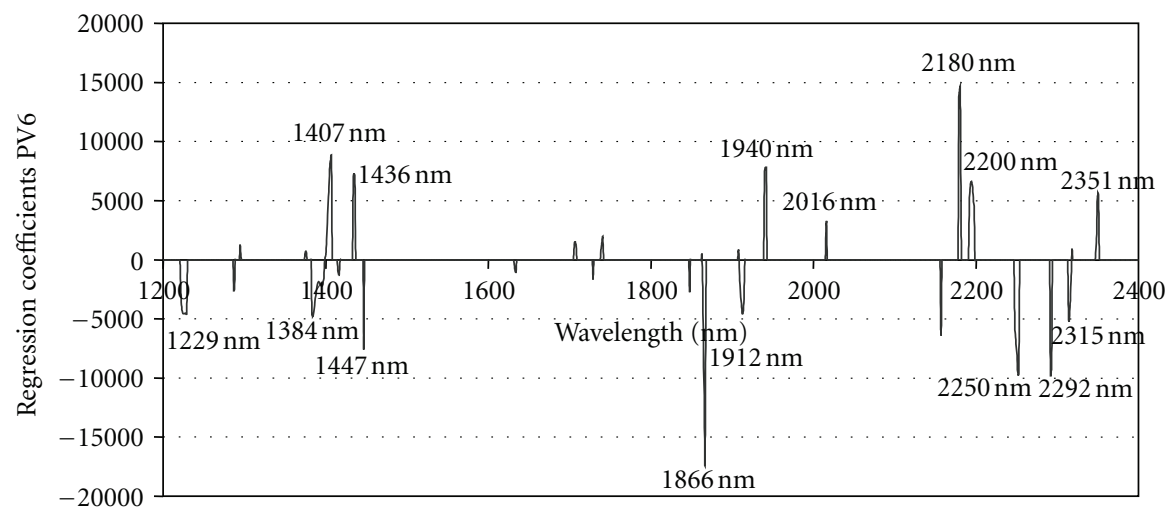

FIGURE 2: PLS regression coefficients accepted for a generic model (cross-validation data set, 64 samples).

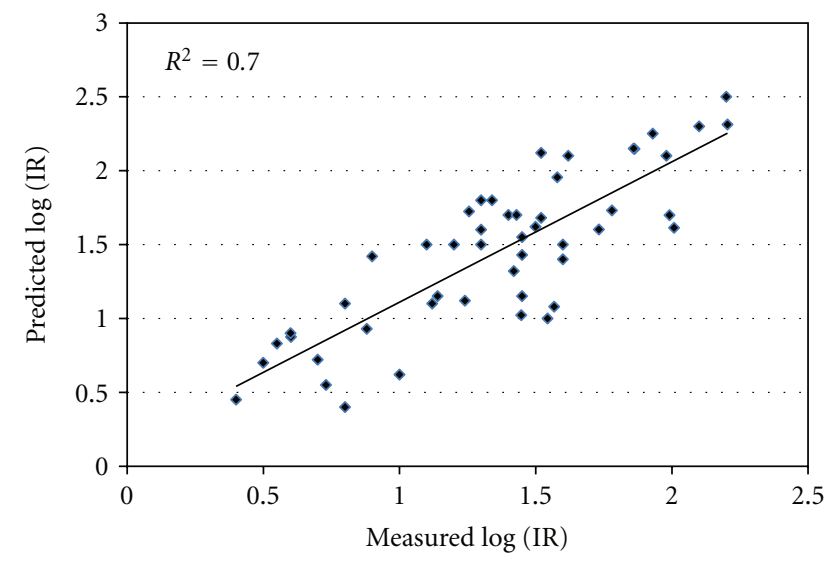

(a)

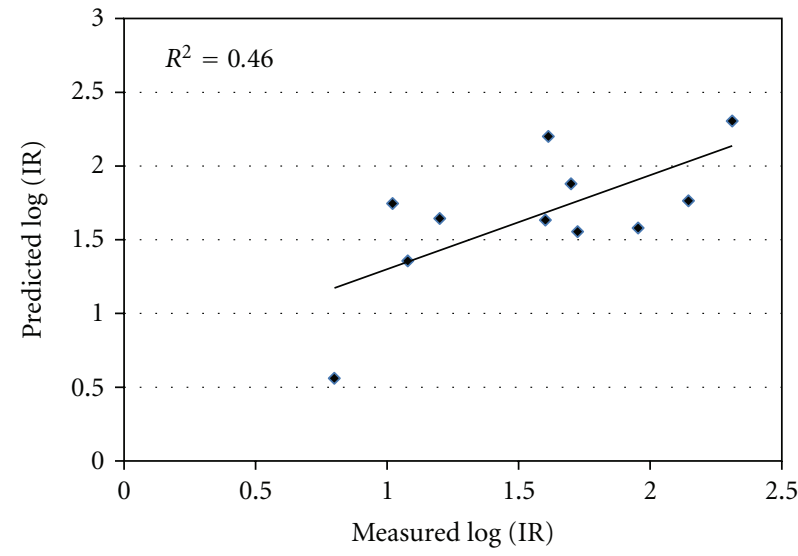

(b)

FIGURE 3: (a) Measured versus predicted values of logarithmically transformed infiltration rates (IR). Results of cross-validation modeling run on the calibration set (53 samples, second derivative of absorbance run on 48 wavelengths). (b) 10 measured versus predicted IRs of the external test set $(N=11$ samples $)$.

reflectance is not linear, ANN methods have the advantage when many soils are being analyzed.

Indeed, when assessing IR by either PLS regression or ANN analyses for heterogeneous sets of soils, the spectral range needs to be reduced by identifying the wavelengths at which the spectral data give the best analytical behavior. In our study, based on results of Marten's test selection, we used the wavelengths highlighted in Figure 2, which are similar to those obtained by Goldshleger et al. [8] and by Ben-Dor et al. [10] for the Israeli soil types. This result confirms that different kinds of soils can be modeled using specific ranges of wavelengths. An additional applicative conclusion that can be drawn from this result is the possibility of constructing a simple sensor for future IR assessment in the field based on specific wavelength regions, with the aim of predicting IR online. The exploration of a larger sample set with other soil types and a wider dynamic (or other) range of IR combinations is warranted.

\section{Concluding Remarks}

Soils from Israel and the US were examined for possible prediction of IR using spectral measurements. We concluded that the ANN approach gives better results for the assessment of IR in a heterogeneous sample set than the PLS regression analysis. We used specific ranges of wavelengths for both models. The calibration models developed and used in this study can be transferred to use with other soils.

When PLS model was run using the raw spectra $(X-$ variables) and also when PLS was run using original not logtransformed values ( $Y$-variable), much lower accuracy of IR were accepted (RMSE 30-50\%) therefore results were not reported. In contrast, raw spectra and original IR values were used in ANN approach, showing an additional advantage of using the ANN approach to assess IR based on raw spectral data using our data set. Note that, although ANN modeling allows high accuracy estimations of soil IR, both approaches 


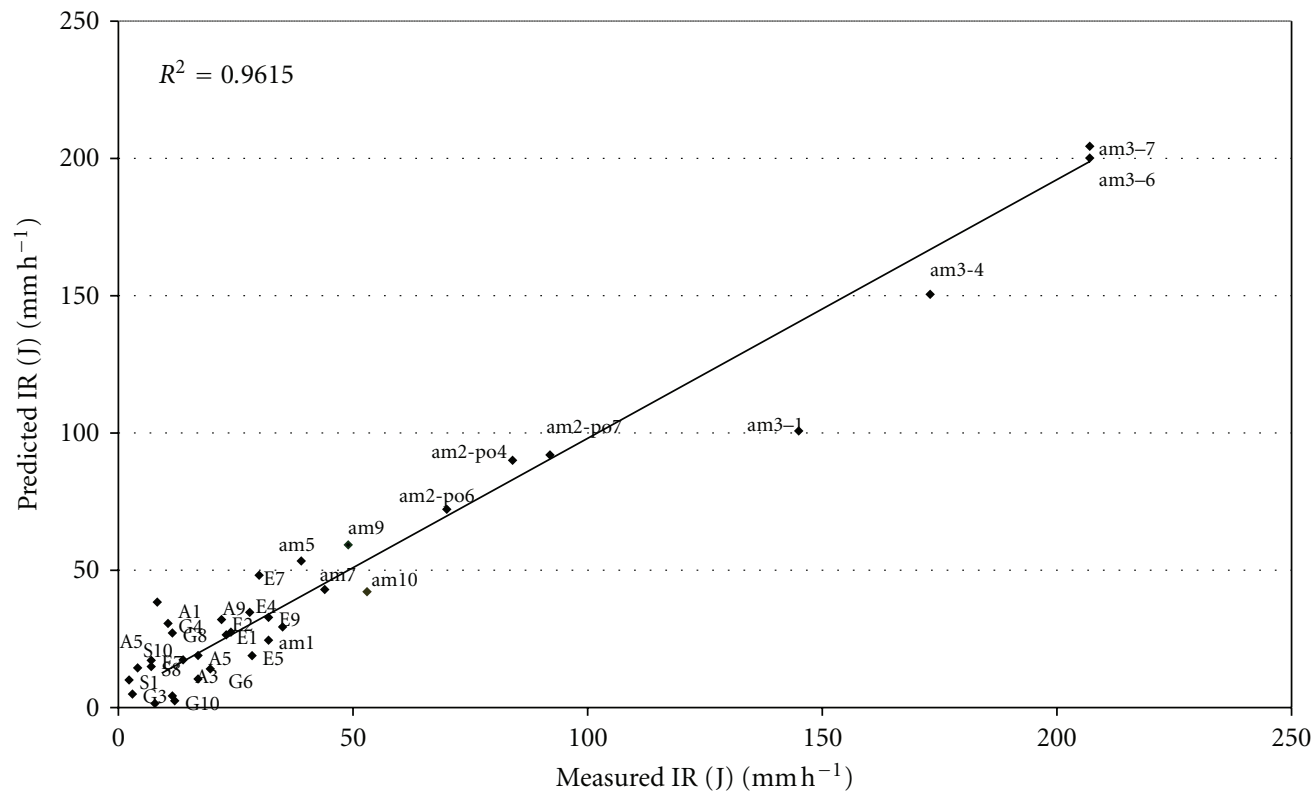

FIGURE 4: Measured versus predicted values of infiltration rate (IR) resulting from ANN analyses. Model run on original reflectance values, 48 wavelengths.

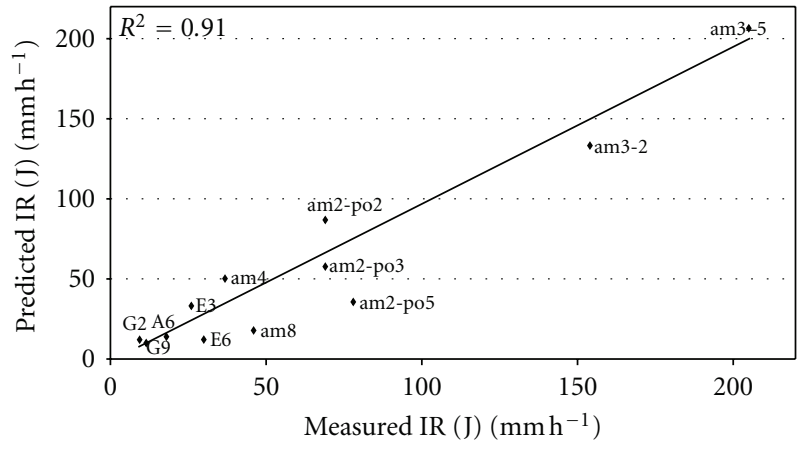

FIGURE 5: ANN results for the test set $(N=11$ samples; same samples were used for PLS analyses).

are dependent on wavelengths selection and such a selection must, therefore, be applied before either model is considered.

Finally, the significant relationships between selected wavelength reads and IR as carried out in the present study indicate that assessment of IR by reflectance spectroscopy is not only feasible but also reliable.

\section{References}

[1] M. Agassi, I. Shainberg, and J. Morin, "Effect of raindrop impact energy and water salinity on infiltration rates of sodic soils," Soil Science Society of America Journal, vol. 45, no. 1, pp. 848-851, 1981.

[2] M. Agassi, J. Morin, and I. Shainberg, "Effect of raindrop impact energy and water salinity on infiltration rates of sodic soils," Soil Science Society of America Journal, vol. 49, no. 1, pp. 186-190, 1985.
[3] S. M. De Jong, "The analysis of spectroscopical data to map soil types and soil crusts of Mediterranean eroded soils," Soil Technology, vol. 5, no. 3, pp. 199-211, 1992.

[4] J. A. M. Demattê, R. C. Campos, M. C. Alves, P. R. Fiorio, and M. R. Nanni, "Visible-NIR reflectance: a new approach on soil evaluation," Geoderma, vol. 121, no. 1-2, pp. 95-112, 2004.

[5] N. Goldshleger, E. Ben-Dor, Y. Benyamini, D. G. Blumberg, and M. Agassi, "Soil crusting and infiltration process as monitored by soil reflectance spectroscopy in the SWIR region," International Journal of Remote Sensing, vol. 23, no. 19, pp. 3909-3920, 2002.

[6] E. Ben Dor, N. Goldshleger, M. Eshel, V. Mirablis, and U. Basson, "Combined active and passive remote sensing methods for assessing soil salinity," in Remote Sensing of Soil Salinization: Impact and Land Management, G. Metternicht and A. Zinck, Eds., pp. 235-255, CRC Press, Boca Raton, Fla, USA, 2009.

[7] N. Goldshleger, E. Ben-Dor, Y. Benyamini, D. Blumberg, and M. Agassi, "The spectral reflectance of soil's structural crust in the SWIR region (1.2-2.5 $\mu \mathrm{m})$," Terra Nova, vol. 13, no. 1, pp. 12-17, 2001.

[8] N. Goldshleger, E. Ben-Dor, Y. Benyamini, and M. Agassi, "Soil reflectance as a tool for assessing physical crust arrangement of four typical soils in Israel," Soil Science, vol. 169, no. 10, pp. 677-687, 2004.

[9] N. Goldshleger, E. Ben-Dor, A. Chudnovsky, and M. Agassi, "Soil reflectance as a generic tool for assessing infiltration rate induced by structural crust for heterogeneous soils," European Journal of Soil Science, vol. 60, no. 6, pp. 1038-1051, 2009.

[10] E. Ben-Dor, N. Goldlshleger, Y. Benyamini, D. G. Blumberg, and M. Agassi, "The spectral reflectance properties of soil structural crusts in the $1.2-$ to $2.5-\mu \mathrm{m}$ spectral region," Soil Science Society of America Journal, vol. 67, no. 1, pp. 289-299, 2003.

[11] E. Ben-Dor, N. Goldshleger, O. Braun et al., "Monitoring infiltration rates in semiarid soils using airborne hyperspectral 
technology," International Journal of Remote Sensing, vol. 25, no. 13, pp. 2607-2624, 2004.

[12] P. Williams and K. Norris, Near-Infrared Technology in The Agricultural and Food Industries, American Association of Cereal Chemists, 1987.

[13] E. Ben-Dor, K. Patkin, A. Banin, and A. Karnieli, "Mapping of several soil properties using DAIS-7915 hyperspectral scanner data-a case study over soils in Israel," International Journal of Remote Sensing, vol. 23, no. 6, pp. 1043-1062, 2002.

[14] R. Clark, "Spectroscopy of rocks and minerals," in Manual of Remote Sensing, A. Rencz, Ed., pp. 3-58, John Wiley \& Sons, 1999.

[15] H. W. Siesler, Y. Ozaki, S. Kawata, and H. M. Heise, Eds., NearInfrared Spectroscopy. Principles, Instruments, Applications, Wiley-VCH, Weinheim, Germany, 2002.

[16] Y. Dan and Z. Raz, Soil Association Map of Israel, Volcani Institute for Agricultural Research, Israel, 1970.

[17] Keys to soil Taxonomy, Soil Survey Staff, "Soil Taxonomy : A system of soil classification for making and interapating soils surveys," US Department of Agriculture, 1999.

[18] E. Ben-Dor and A. Banin, "Visible and near infrared (0.4$1.1 \mathrm{~mm}$ ) analysis of arid and semi arid soils," Remote Sensing of Environment, vol. 48, no. 3, pp. 261-274, 1995.

[19] L. Kooistra, R. Wehrens, W. Leuven, and L. Buydens, "Possibilities of visible-near-infrared spectroscopy for the assessment of soil contamination in river floodplains," Analytica Chimica Acta, vol. 446, no. 1-2, pp. 97-105, 2001.

[20] L. Kooistra, G. Wanders, R. Epemac, W. Leuven, L. Wehrens, and L. Buydens, "The potential of field spectroscopy for the assessment of sediment properties in river floodplains," Analytica Chimica Acta, vol. 484, no. 2, pp. 189-200, 2003.

[21] G. I. Metternicht and J. A. Zinck, "Remote sensing of soil salinity: potentials and constraints," Remote Sensing of Environment, vol. 85, no. 1, pp. 1-20, 2003.

[22] R. A. Viscarra Rossel, R. N. McGlynn, and A. B. McBratney, "Determining the composition of mineral-organic mixes using UV-vis-NIR diffuse reflectance spectroscopy," Geoderma, vol. 137, no. 1-2, pp. 70-82, 2006.

[23] R. A. Viscarra Rossel and T. Behrens, "Using data mining to model and interpret soil diffuse reflectance spectra," Geoderma, vol. 158, no. 1-2, pp. 46-54, 2010.

[24] T. Owen, "Advances in UV-VIS spectroscopy," Derivative Spectroscopy, vol. 1, pp. 58-64, 1987.

[25] F. Tsai and W. D. Philpot, "A derivative-aided hyperspectral image analysis system for land-cover classification," IEEE Transactions on Geoscience and Remote Sensing, vol. 40, no. 2, pp. 416-425, 2002.

[26] T. Udelhoven, C. Emmerling, and T. Jarmer, "Quantitative analysis of soil chemical properties with diffuse reflectance spectrometry and partial least-square regression: a feasibility study," Plant and Soil, vol. 251, no. 2, pp. 319-329, 2003.

[27] J. Moros, M. J. Martínez-Sánchez, C. Pérez-Sirvent, S. Garrigues, and M. de la Guardia, "Testing of the region of Murcia soils by near infrared diffuse reflectance spectroscopy and chemometrics," Talanta, vol. 78, no. 2, pp. 388-398, 2009.

[28] S. Wold, M. Sjöström, and L. Eriksson, "PLS-regression: a basic tool of chemometrics," Chemometrics and Intelligent Laboratory Systems, vol. 58, no. 2, pp. 109-130, 2001.

[29] D. Brown, K. Shepherd, M. Walsh, M. Mays, and T. Reinsch, "Global soil characterization with VNIR diffuse reflectance spectroscopy," Geoderma, vol. 132, no. 3-4, pp. 273-290, 2006.
[30] D. J. Brown, "Using a global VNIR soil-spectral library for local soil characterization and landscape modeling in a 2ndorder Uganda watershed," Geoderma, vol. 140, no. 4, pp. 444453, 2007.

[31] R. Hecht-Nielsen, Neurocomputing, Addison-Wesley, 1990.

[32] C.-C. Yang, S. O. Prasher, P. Enright et al., "Application of decision tree technology for image classification using remote sensing data," Agricultural Systems, vol. 76, no. 3, pp. 11011117, 2003.

[33] J. Farifteh, F. Van der Meer, C. Atzberger, and E. Carranza, "Quantitative analysis of salt-affected soil reflectance spectra: a comparison of two adaptive methods (PLSR \& ANN)," Remote Sensing of Environment, vol. 110, no. 1, pp. 59-78, 2007.

[34] J. Morin, D. Goldberg, and I. Singer, "Rainfall simulator with rotating disk," Transactions of the American Society of Agricultural Engineers, vol. 10, pp. 74-77, 1967.

[35] K. Esbensen, Multivariate Data Analyses. An Introduction to Multivariate Data Analyses and Experimental Design, Aalborg University, Esbjerg, Denmark, 5th edition, 2002.

[36] A. J. Adeloye and A. De Munari, "Artificial neural network based generalized storage-yield-reliability models using the Levenberg-Marquardt algorithm," Journal of Hydrology, vol. 326, no. 1-4, pp. 215-230, 2006.

[37] H. Demuth and M. Beale, Neural Network Toolbox for Use with Matlab, The MathWorks, Natick, Mass, USA, 2004.

[38] A. M. Mouazen, W. Saeys, J. Xing, J. De Baerdemaeker, and H. Ramon, "Near infrared spectroscopy for agricultural materials: an instrument comparison," Journal of Near Infrared Spectroscopy, vol. 13, no. 2, pp. 87-97, 2005.

[39] G. R. Hunt, "Spectral signatures of particulate minerals, in the visible and near-infrared," Geophysics, vol. 42, no. 3, pp. 501513, 1977.

[40] G. R. Hunt, J. W. Salisbury, and A. Lenhoff, "Visible and nearinftatrd spectra of minerals and rocks," IIIoxides and Hydroxides Modern Geology, vol. 2, pp. 195-205, 1971. 

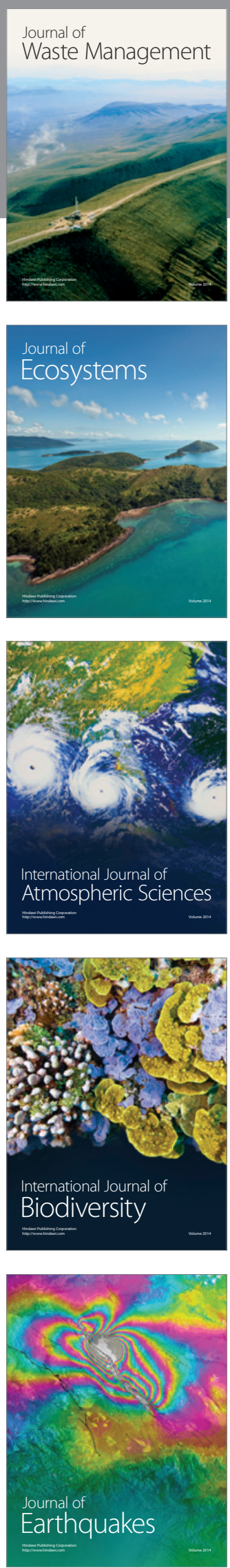
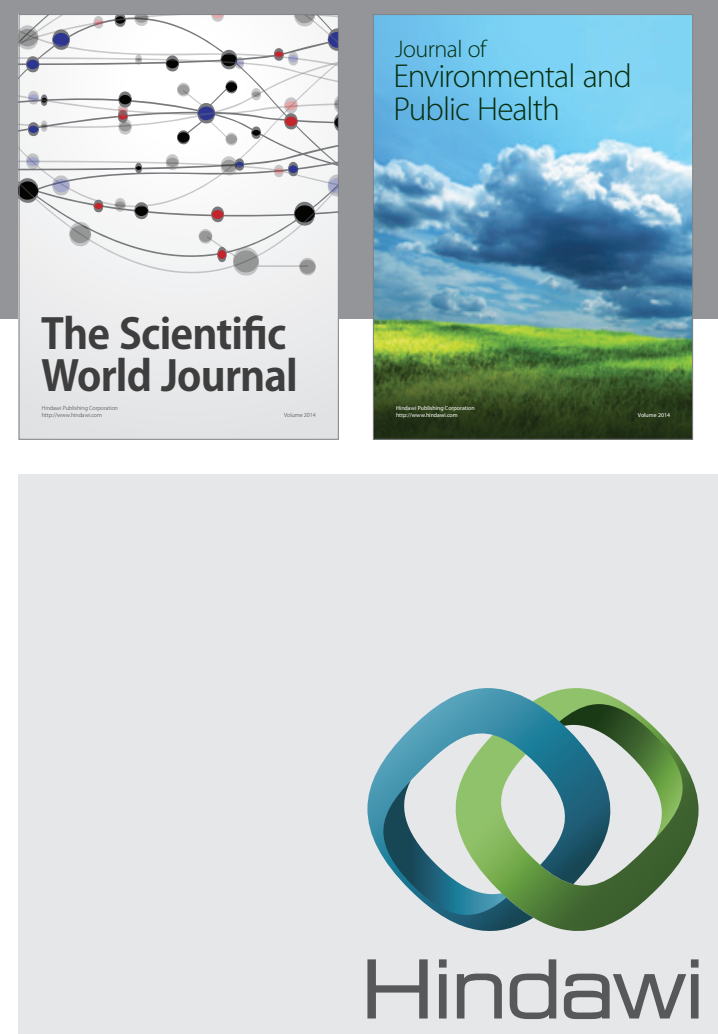

Submit your manuscripts at

http://www.hindawi.com
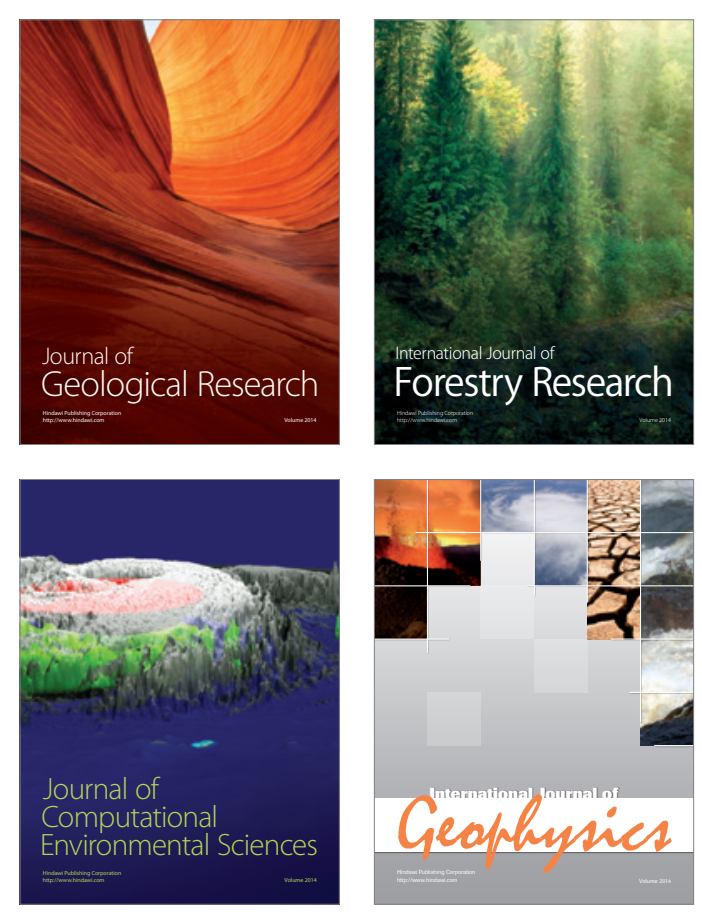
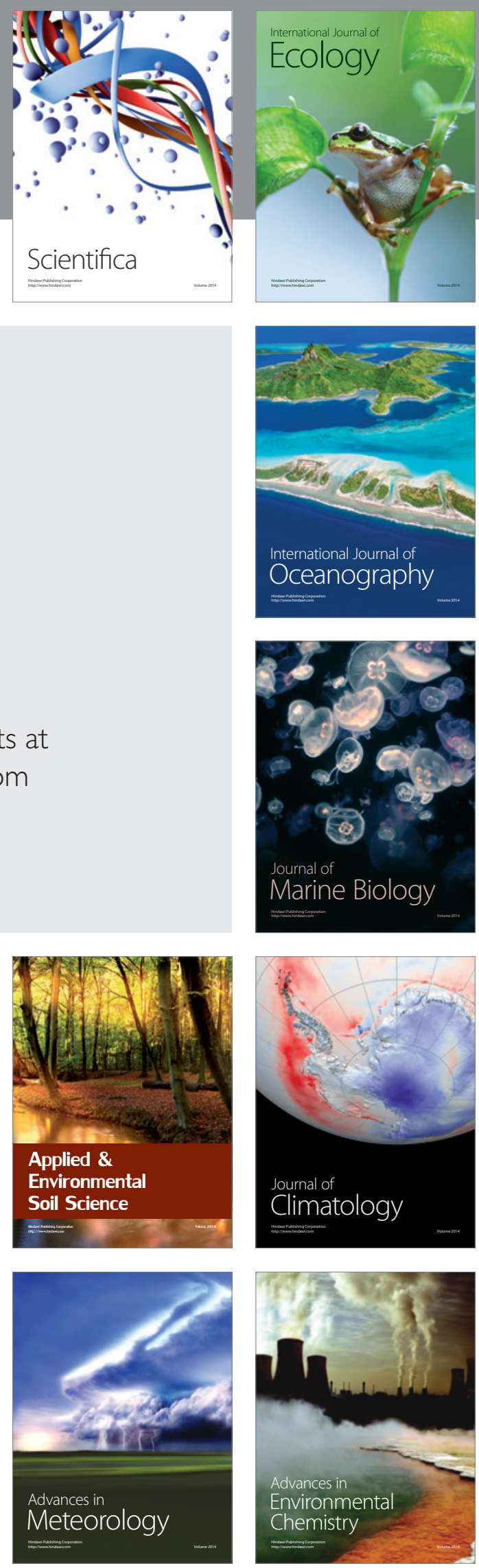